\title{
Desempenho de bezerros alimentados com dietas líquidas à base de leite integral ou soro de leite
}

[Performance of calves fed on liquid diets based on whole milk and whey]

\author{
F.A.P.V. Fontes ${ }^{1}$, S.G. Coelho ${ }^{2 *}$, A.M.Q. Lana ${ }^{2}$, T.C. Costa ${ }^{3}$, A.U. Carvalho ${ }^{2}$, \\ M.I.C. Ferreira ${ }^{3}$, H.M. Saturnino ${ }^{2}$, R.B. Reis ${ }^{2}$, A.L. Serrano ${ }^{4}$ \\ ${ }^{1}$ Médica veterinária autônoma \\ ${ }^{2}$ Escola de Veterinária - UFMG \\ Caixa Postal 567 \\ 30123-970 - Belo Horizonte, MG \\ ${ }^{3}$ Aluna de pós-graduação - EV-UFMG \\ ${ }^{4}$ Aluno de graduação - EV-UFMG
}

\begin{abstract}
RESUMO
Quinze bezerros da raça Holandesa, desaleitados aos 30 dias de idade, foram utilizados para avaliar os efeitos da inclusão de fontes protéicas alternativas, em substituição às proteínas do leite integral, na formulação de sucedâneos do leite. Os animais foram divididos em três grupos: o grupo controle (C) recebeu leite em pó integral reconstituído; o grupo sucedâneo SL (soro/leite) recebeu 41,6\% da proteína bruta (PB) vinda do concentrado protéico de soro (CPS), 23,1\% do soro de leite e 35,3\% do leite em pó integral; e o grupo sucedâneo S (soro) recebeu $68 \%$ da PB vinda do CPS e $32 \%$ do soro de leite. O consumo de concentrado, feno, sal mineral e água foi mensurado diariamente, enquanto o ganho de peso foi avaliado semanalmente. Não houve diferença $(\mathrm{P}>0,05)$ para o consumo de concentrado, sal mineral e água entre os grupos, nos períodos avaliados. $\mathrm{O}$ consumo de feno e o ganho de peso foram inferiores nos animais do grupo $\mathrm{S}(\mathrm{P}<0,05)$. A substituição de $100 \%$ do leite integral por CPS e soro de leite influenciou negativamente o desempenho.
\end{abstract}

Palavras-chave: bezerro, sucedâneos, concentrado protéico de soro, soro de leite, desempenho

\begin{abstract}
The effects of alternative protein sources replacing whole milk proteins in milk replacer formulation were evaluated. Fifteen Holstein calves, weaned at 30 days of age, were used to evaluate the intake of concentrate, hay, mineral salt and water, and live weight gain. Animals were divided in three experimental groups: control group $(C)$ - fed whole milk; milk replacer WM group (whey/milk) - fed on $41.6 \%$ of crude protein (CP) provided by whey protein concentrate (WPC), $23.1 \%$ by whey and $35.3 \%$ by whole milk; and milk replacer W group (whey) - fed on $68 \%$ of CP provided by WPC and $32 \%$ by whey. Starter, hay, mineral and water intakes were daily measured, whereas live weight was weekly recorded. Starter, mineral and water intakes were not different $(P>0.05)$ among the experimental groups. Hay intake and live weight gain were lower $(P<0.05)$ for $S$ group animals. Total replacement of whole milk proteins with whey proteins negatively affected the performance of the calves.
\end{abstract}

Keywords: calf, milk replacer, whey protein concentrate, whey, performance

Recebido em 4 de maio de 2005

Aceito em 27 de fevereiro de 2006

*Autor para correspondência (corresponding author)

E-mail: sandra@vet.ufmg.br 


\section{INTRODUÇÃO}

Os custos de criação de animais de reposição representam entre $15 \%$ e $20 \%$ dos custos totais na maioria das fazendas leiteiras, sendo que 50\% a $60 \%$ destes gastos advêm da alimentação das bezerras e novilhas. Durante o aleitamento, os custos diários são maiores que durante qualquer outra fase da recria, e isso se deve, em parte, ao custo alto da dieta líquida, além dos gastos referentes ao manejo dos animais (Davis e Drackley, 1998).

Sucedâneos podem ser definidos como produtos destinados a substituir o leite de vaca na fase de aleitamento dos bezerros (Crane, 1991). O uso desses produtos permite aos produtores a venda de maior volume de leite, com conseqüente aumento da disponibilidade para a indústria e para a alimentação humana. Entretanto, o aumento da lucratividade do sistema de criação está na dependência direta das relações de custo/benefício dos produtos utilizados.

Os fatores críticos que influenciam o uso de fontes protéicas nas dietas líquidas de bezerros incluem a digestibilidade relacionada à idade, o perfil dos aminoácidos (AA) e a presença de fatores antinutricionais (Davis e Drackley, 1998).

As proteínas do soro de leite têm alto valor biológico, e sua utilização na alimentação humana e animal permite, ainda, a redução da liberação de resíduos poluentes no meio ambiente $e$ o aumento na margem de lucratividade da indústria.

O objetivo deste trabalho foi desenvolver sucedâneos do leite para bezerros utilizando fontes protéicas que possam tornar seu custo inferior ao do leite, sem comprometimento do desempenho dos animais.

\section{MATERIAL E MÉTODOS}

O experimento foi realizado entre abril e outubro de 2003, utilizando 15 bezerros machos da raça Holandesa, provenientes de várias fazendas. Ao nascimento, nas fazendas de origem, os animais receberam colostro proveniente de um "banco de colostro" e, em seguida, foram transportados para o local do experimento, onde, após serem submetidos à inspeção clínica para registro das condições físicas, receberam outros quatro litros de colostro e foram alojados em gaiolas de ferro individuais, suspensas do solo, com piso ripado de madeira e equipadas com balde para água, feno e concentrado, e cocho para sal mineral.

Até o terceiro dia de vida, a dieta líquida constituiu-se de colostro e leite em pó reconstituído. Após esse período, os animais foram divididos em três grupos, de acordo com a dieta líquida fornecida: os do grupo-controle (C) receberam leite em pó integral reconstituído, os do grupo sucedâneo soro/leite(SL), $41,6 \%$ da proteína bruta(PB) oriunda do CPS, $23,1 \%$ do soro de leite e $35,3 \%$ do leite em pó integral, e os do grupo sucedâneo soro (S), $68 \%$ da PB oriunda do CPS e $32 \%$ do soro de leite. A formulação e o custo dos sucedâneos experimentais encontram-se na Tab.1, e a composição nutricional, na Tab.2.

Tabela 1. Ingredientes, níveis de inclusão e custos, expressos em porcentagem da matéria seca (MS), das formulações dos sucedâneos fornecidos para bezerros

\begin{tabular}{|c|c|c|}
\hline Ingrediente & $\begin{array}{c}\text { Sucedâneo } \\
\text { SL }\end{array}$ & $\begin{array}{c}\text { Sucedâneo } \\
\text { S }\end{array}$ \\
\hline CPS & 10,7 & 17,5 \\
\hline Soro em pó & 35,5 & 49,0 \\
\hline Leite em pó integral & 28,0 & - \\
\hline Glicose de milho & 9,4 & 10,5 \\
\hline Banha suína & 10,0 & 18,5 \\
\hline Premix vitamínico-mineral & 1,0 & 1,0 \\
\hline Lecitina de soja & 1,0 & 1,0 \\
\hline Inerte & 3,3 & - \\
\hline Fosfato bicálcico & 1,1 & 2,0 \\
\hline Calcário calcítico & - & 0,6 \\
\hline Custo $(\mathrm{kg} / \mathrm{MS})^{1}$ & $\mathrm{R} \$ 6,62$ & $\mathrm{R} \$ 6,28$ \\
\hline Custo (litro diluído) ${ }^{1}$ & $\mathrm{R} \$ 0,92$ & $\mathrm{R} \$ 0,87$ \\
\hline
\end{tabular}


Tabela 2. Teores médios de matéria seca (MS), proteína bruta (PB), extrato etéreo (EE), fibra bruta (FB), fibra em detergente neutro (FDN), fibra em detergente ácido (FDA), cálcio $(\mathrm{Ca})$, fósforo $(\mathrm{P})$, lactose $\mathrm{e}$ energia metabolizável (EM), do leite em pó integral dos sucedâneos SL e S do concentrado e feno de Tifton 85, expressos em porcentagem da matéria seca, fornecidos para bezerros

\begin{tabular}{lccccc}
\hline & Leite em pó integral & Sucedâneo SL & Sucedâneo S & Concentrado & Feno \\
\hline MS (\%) & 92,3 & 93,6 & 94,0 & 89,2 & 90,3 \\
PB (\%) & 26,5 & 25,8 & 26,0 & 21,7 & 11,3 \\
EE (\%) & 27,0 & 19,3 & 19,0 & 3,1 & 1,8 \\
FB (\%) & 1,15 & 1,3 & 1,4 & - & - \\
FDN (\%) & - & - & - & - & 83,9 \\
FDA (\%) & - & - & - & - & 40,8 \\
Ca (\%) & 1,04 & 1,08 & 1,03 & 1,9 & 0,48 \\
P (\%) & 0,69 & 0,67 & 0,65 & 0,96 & -32 \\
Lactose (\%) $_{\text {EM }^{2}(\mathrm{Mcal} / \mathrm{kg})}^{39,2^{1}}$ & $4,85^{1}$ & $39,5^{2}$ & $39,6^{2}$ & - & - \\
\hline${ }^{1}$ Segundo o (Nutrient. & $4,35^{2}$ & $4,39^{2}$ & - & - \\
\hline
\end{tabular}

Segundo o (Nutrient..., 2001). SL = soro/leite; $\mathrm{S}=$ soro.

${ }^{2}$ Valores calculados com base nos ingredientes utilizados, de acordo com o NRC (Nutrient..., 2001).

Os sucedâneos experimentais foram produzidos em fábrica de rações. Para os animais do grupo controle, foi fornecido leite em pó integral reconstituído, cuja composição nutricional encontra-se na Tab. 2. O leite e os sucedâneos foram preparados imediatamente antes das refeições, sendo as diluiçoões baseadas nos teores de MS de cada formulação, visando atingir 13\% de MS no produto diluído. As dietas líquidas foram fornecidas em baldes, duas vezes ao dia, sendo dois litros às sete horas e dois litros às 16 horas, até a quarta semana de idade. Da quinta à oitava semana, os bezerros receberam a mesma dieta sólida. Esse procedimento visou avaliar o desempenho dos diferentes grupos após o desaleitamento.

Todos os animais receberam a mesma dieta sólida, composta por concentrado (Tab. 2), feno (Tab. 2) e sal mineral (Tab. 3), fornecidos à vontade, a partir do terceiro dia de idade.

Tabela 3. Níveis de garantia dos elementos ativos do sal mineral, por $\mathrm{kg}$ do produto, fornecidos para bezerros

\begin{tabular}{lc}
\hline Mineral & Níveis de garantia \\
\hline Cálcio & $240 \mathrm{~g}$ \\
Fósforo & $174 \mathrm{~g}$ \\
Cobalto & $100 \mathrm{mg}$ \\
Cobre & $1.250 \mathrm{mg}$ \\
Ferro & $1795 \mathrm{mg}$ \\
Iodo & $90 \mathrm{mg}$ \\
Manganês & $2.000 \mathrm{mg}$ \\
Selênio & $15 \mathrm{mg}$ \\
Zinco & $5.270 \mathrm{mg}$ \\
Flúor & $1.740 \mathrm{mg}$ \\
${ }^{*}$ Solubilidade ácido cítrico $2 \%-95 \%$. &
\end{tabular}

Para medir o consumo de água, descontou-se a evaporação, por meio de um balde de referência, colocado próximo às gaiolas, no mesmo horário e com a mesma quantidade oferecida aos animais. As medidas de consumo e evaporação foram feitas utilizando-se um balde graduado com capacidade para 20 litros.

As pesagens dos animais foram realizadas quando de sua chegada ao local do experimento, e a cada sete dias, antes do fornecimento de alimentos. Amostras dos alimentos e das sobras foram colhidas quinzenalmente para determinação dos teores de $\mathrm{MS}$ a $105^{\circ} \mathrm{C}, \mathrm{PB}$, cálcio e fósforo (Official..., 1980), e componentes da parede celular pelo método seqüencial de Van Soest et al. (1991).

$\mathrm{O}$ experimento foi realizado seguindo $\mathrm{o}$ delineamento estatístico inteiramente ao acaso. As análises foram feitas utilizando-se os procedimentos do software SAEG (Sistemas..., 1998). As variáveis foram analisadas em esquema de parcelas subdivididas, sendo apresentadas as dietas nas parcelas e as semanas nas subparcelas. As variáveis que não apresentaram normalidade e/ou homogeneidade foram submetidas a transformações logarítmicas. Para testar as diferenças entre as médias, utilizou-se o teste Duncan a $5 \%$ de probabilidade.

\section{RESULTADOS E DISCUSSÃO}

Os dados referentes ao consumo médio diário de concentrado na matéria seca, da primeira à oitava 
semana de vida dos bezerros, podem ser observados na Tab. 4.

Não houve diferença $(\mathrm{P}>0,05)$ entre os grupos experimentais, entretanto, o consumo foi diferente entre as semanas $(\mathrm{P}<0,05)$. Observa-se elevação crescente no consumo com o avançar da idade, explicado pelo crescimento dos animais, ocasionando aumento de suas exigências nutricionais. Com o fornecimento de quantidades fixas de leite, os animais passam a buscar outros alimentos para suprir suas necessidades crescentes. Segundo Quigley III e Bernard (1996), o consumo de concentrado aumenta rapidamente entre a terceira e a sexta semanas de vida, com diminuição do ritmo nas próximas quatro a seis semanas. No presente trabalho, houve aumento acelerado até a quinta semana, tornando-se mais lento entre a sexta e a oitava semanas. Ao desaleitamento, o maior aumento justifica-se, pois o concentrado tornouse a principal fonte de nutrientes.

Tabela 4. Consumo médio diário de matéria seca de concentrado, expresso em g/animal/dia, por bezerros, da primeira à oitava semana de vida, aleitados até os 30 dias com leite $(\mathrm{C})$, sucedâneo soro/leite $(\mathrm{SL})$ ou sucedâneo soro (S)

\begin{tabular}{lccccccccc}
\hline \multirow{2}{*}{ Grupo } & \multicolumn{7}{c}{ Semana } & \multirow{2}{*}{ Média } \\
\cline { 2 - 9 } & 1 & 2 & 3 & 4 & 5 & 6 & 7 & 8 & \\
\hline C & 73,8 & 129,8 & 295,8 & 434,9 & 769,3 & 880,5 & 1166,3 & 1473,3 & $653,0 \mathrm{~A}$ \\
SL & 60,7 & 191,3 & 376,7 & 617,4 & 921,5 & 1080,4 & 1107,3 & 1401,2 & $719,6 \mathrm{~A}$ \\
S & 43,9 & 136,7 & 279,7 & 473,7 & 683,0 & 750,8 & 728,4 & 960,8 & $507,1 \mathrm{~A}$ \\
Média & $59,5 \mathrm{~g}$ & $152,6 \mathrm{f}$ & $317,4 \mathrm{e}$ & $508,7 \mathrm{~d}$ & $791,3 \mathrm{c}$ & $903,9 \mathrm{bc}$ & $1000,7 \mathrm{~b}$ & $1278,4 \mathrm{a}$ & \\
\hline
\end{tabular}

Médias seguidas por letras distintas minúsculas na linha ou maiúsculas na coluna diferem entre si (entre semanas e entre grupos experimentais, respectivamente ). $\mathrm{CV}=38,9 \%$; Teste Duncan $(\mathrm{P}<0,05)$.

A equação de regressão que melhor representa o consumo de concentrado $\left(\mathrm{R}^{2}=0,98\right)$ foi: $\mathrm{Y}=-0,00017+0,0001764 \mathrm{X}$, em que $\mathrm{Y}$ representa o consumo de concentrado e $\mathrm{X}$ a semana experimental.

$\mathrm{Na}$ Tab. 5 encontram-se os dados médios de consumo de matéria seca de feno, ao longo das semanas experimentais. O consumo de feno foi diferente entre semanas e grupos $(\mathrm{P}<0,05)$, mas não houve interação. Os animais do grupo $\mathrm{S}$ consumiram menos feno $(\mathrm{P}<0,05)$. À semelhança do que ocorreu com o concentrado, houve aumento no consumo com o avançar da idade, principalmente após o desaleitamento.

Tabela 5. Consumo médio diário de matéria seca de feno, expresso em g/animal/dia, por bezerros da primeira à oitava semana de vida, aleitados até os 30 dias com leite (C), sucedâneo soro/leite (SL) ou sucedâneo soro (S)

\begin{tabular}{llllllllll}
\hline \multirow{2}{*}{ Grupo } & \multicolumn{7}{c}{ Semana } & Média \\
\cline { 2 - 8 } & 1 & 2 & 3 & 4 & 5 & 6 & 7 & 8 & \\
\hline C & 2,8 & 1,5 & 9,6 & 26,0 & 26,6 & 50,9 & 54,4 & 76,4 & $31,0 \mathrm{~A}$ \\
SL & 10,8 & 1,3 & 4,2 & 19,2 & 30,6 & 50,8 & 47,2 & 64,9 & $28,6 \mathrm{~A}$ \\
S & 5,5 & 0,2 & 1,1 & 5,2 & 6,5 & 20,8 & 27,3 & 25,7 & $11,5 \mathrm{~B}$ \\
Média & $6,4 \mathrm{c}$ & $1,0 \mathrm{~d}$ & $5,0 \mathrm{c}$ & $16,8 \mathrm{~b}$ & $21,2 \mathrm{~b}$ & $40,8 \mathrm{a}$ & $43,0 \mathrm{a}$ & $55,7 \mathrm{a}$ & \\
\hline
\end{tabular}

Médias seguidas por letras distintas minúsculas na linha ou maiúsculas na coluna diferem entre si (entre semanas e entre grupos experimentais, respectivamente). $\mathrm{CV}=22 \%$; Teste Duncan $(\mathrm{P}<0,05)$.

Observações visuais durante o experimento indicaram que a procura do feno pelos bezerros foi baixa, principalmente durante a fase de aleitamento, e pareceu estar relacionada à tentativa do animal em regular o $\mathrm{pH}$ ruminal. Bezerros que apresentavam consumos muito elevados de concentrado em um determinado dia geralmente consumiam mais feno no dia subseqüente.

Não foi possível estabelecer uma equação de regressão englobando a primeira e a segunda 
semanas experimentais. Assim, a equação que melhor representa o consumo de feno $\left(\mathrm{R}^{2}=0,96\right)$, da terceira à oitava semanas foi: $\mathrm{Y}=-24,82+10,043 \mathrm{X}$, em que $\mathrm{Y}$ representa $\mathrm{o}$ consumo de feno e $\mathrm{X}$ a semana experimental.
O consumo de sal mineral, da primeira à oitava semana de vida, é apresentado na Tab. 6. Não houve diferença $(\mathrm{P}>0,05)$ entre os grupos, entretanto, o consumo foi diferente entre as semanas $(\mathrm{P}<0,05)$.

Tabela 6. Consumo diário de sal mineral, expresso em g/animal/dia, por bezerros da primeira à oitava semana de vida, aleitados até os 30 dias com leite, sucedâneo soro/leite (SL) ou sucedâneo soro (S)

\begin{tabular}{lccccccccc}
\hline \multirow{2}{*}{ Grupo } & \multicolumn{7}{c}{ Semana } & \multicolumn{1}{c}{ Média } \\
\cline { 2 - 8 } & 1 & 2 & 3 & 4 & 5 & 6 & 7 & 8 & \\
\hline $\mathrm{C}$ & 34,2 & 22,6 & 21,9 & 15,3 & 15,5 & 8,6 & 5,1 & 3,6 & $15,9 \mathrm{~A}$ \\
$\mathrm{SL}$ & 15,8 & 8,8 & 10,0 & 4,4 & 7,6 & 5,5 & 6,7 & 3,4 & $7,8 \mathrm{~A}$ \\
$\mathrm{~S}$ & 19,6 & 14,8 & 11,0 & 6,5 & 7,8 & 8,9 & 4,2 & 7,8 & $10,1 \mathrm{~A}$ \\
Média & $23,2 \mathrm{a}$ & $15,4 \mathrm{bc}$ & $14,3 \mathrm{bc}$ & $8,7 \mathrm{c}$ & $10,3 \mathrm{bc}$ & $7,7 \mathrm{c}$ & $5,3 \mathrm{~cd}$ & $4,9 \mathrm{~d}$ & \\
\hline
\end{tabular}

Médias seguidas por letras distintas minúsculas na linha ou maiúsculas na coluna diferem entre si (entre semanas e entre grupos experimentais, respectivamente). $\mathrm{CV}=20,1 \%$; Teste Duncan $(\mathrm{P}<0,05)$.

Ao contrário do concentrado e do feno, o consumo de sal mineral declinou com o avançar da idade. Essa observação indica que à medida que a dieta líquida passa a ter menor contribuição proporcional no suprimento das exigências nutricionais dos animais, ocorre queda no consumo de sal, provavelmente em função do aporte de minerais do concentrado.

$\mathrm{Na}$ Tab. 7 apresentam-se os dados de consumo de água, ao longo das semanas experimentais. Não houve diferença $(\mathrm{P}>0,05)$ entre os grupos experimentais, sugerindo que todas as dietas líquidas apresentaram valores de osmolaridade semelhantes. Entretanto, o consumo de água entre as semanas foi diferente $(\mathrm{P}<0,05)$. Houve elevação do consumo de água com o avançar da idade, principalmente após o desaleitamento, o que está relacionado com a ausência de suprimento de água contida no leite e no sucedâneo, e aos aumentos no consumo de matéria seca e no peso dos animais.

A equação de regressão que melhor representa o consumo de água ao longo das semanas $\left(\mathrm{R}^{2}=\right.$ 0,81) foi: $\mathrm{Y}=-0,2289+0,4784 \mathrm{X}$, em que $\mathrm{Y}$ representa o consumo de água e $\mathrm{X}$ a semana experimental.

Os dados de ganho de peso diário, ao longo das oito primeiras semanas de vida dos bezerros, são apresentados na Tab. 8. O ganho de peso foi diferente entre os grupos experimentais e semanas $(\mathrm{P}<0,05)$, mas não houve interação. $\mathrm{O}$ ganho de peso dos animais do grupo $\mathrm{S}$ foi $34 \%$ inferior ao dos demais grupos.

Tabela 7. Consumo de água, expresso em 1/animal/dia, por bezerros da primeira à oitava semana de vida, aleitados até os 30 dias com leite, sucedâneo soro/leite (SL) ou sucedâneo soro (S)

\begin{tabular}{|c|c|c|c|c|c|c|c|c|c|}
\hline \multirow{2}{*}{ Grupo } & \multicolumn{8}{|c|}{ Semanas } & \multirow{2}{*}{ Média } \\
\hline & 1 & 2 & 3 & 4 & 5 & 6 & 7 & 8 & \\
\hline $\mathrm{C}$ & 2,0 & 1,2 & 1,1 & 1,6 & 2,3 & 3,1 & 3,2 & 4,7 & $2,4 \mathrm{~A}$ \\
\hline SL & 0,6 & 0,7 & 0,5 & 0,8 & 1,9 & 3,6 & 3,2 & 3,6 & $1,9 \mathrm{~A}$ \\
\hline $\mathrm{S}$ & 0,2 & 0,5 & 0,3 & 0,3 & 1,6 & 3,4 & 2,9 & 2,9 & $1,5 \mathrm{~A}$ \\
\hline Média & $0,9 \mathrm{c}$ & $0,8 \mathrm{c}$ & $0,6 \mathrm{c}$ & $0,9 \mathrm{c}$ & $1,9 b$ & $3,4 a$ & $3,1 \mathrm{a}$ & $3,7 \mathrm{a}$ & \\
\hline
\end{tabular}

Médias seguidas por letras distintas minúsculas na linha ou maiúscula na coluna diferem entre si (entre semanas e entre grupos experimentais, respectivamente ). $\mathrm{CV}=20,6 \%$; Teste Duncan $(\mathrm{P}<0,05)$. 
Tabela 8. Ganho de peso, expresso em kg/animal/dia, por bezerros da primeira à oitava semanas de vida, aleitados até os 30 dias com leite (C), sucedâneo soro/leite (SL) ou sucedâneo soro (S)

\begin{tabular}{lccccccccc}
\hline \multirow{2}{*}{ Grupo } & \multicolumn{8}{c}{ Semana } & \multirow{2}{*}{ Média } \\
\cline { 2 - 8 } & 1 & 2 & 3 & 4 & 5 & 6 & 7 & 8 & $0,35 \mathrm{~A}$ \\
$\mathrm{C}$ & 0,18 & 0,07 & 0,21 & 0,36 & 0,06 & 0,78 & 0,63 & 0,47 & $0,29 \mathrm{~A}$ \\
$\mathrm{SL}$ & 0,09 & 0,16 & 0,30 & 0,35 & 0,19 & 0,30 & 0,21 & 0,49 & $0,18 \mathrm{~B}$ \\
$\mathrm{~S}$ & 0,01 & 0,07 & 0,09 & 0,30 & 0,06 & 0,48 & 0,26 & 0,15 & \\
Média & $0,09 \mathrm{c}$ & $0,10 \mathrm{c}$ & $0,20 \mathrm{~b}$ & $0,34 \mathrm{ab}$ & $0,10 \mathrm{c}$ & $0,52 \mathrm{a}$ & $0,37 \mathrm{ab}$ & $0,37 \mathrm{ab}$ & \\
\hline
\end{tabular}

Médias seguidas por letras distintas minúsculas na linha ou maiúsculas na coluna diferem entre si (entre semanas e entre grupos experimentais, respectivamente ). $\mathrm{CV}=6,9 \%$; Teste Duncan $(\mathrm{P}<0,05)$.

Em todos os grupos, houve diminuição no ritmo de ganho de peso na quinta semana de idade. Isso indica que, ao desaleitamento, os animais não conseguiram manter a ingestão de matéria seca apresentada no período de aleitamento. A partir da sexta semana, os animais já apresentam ganhos superiores aos observados antes do desaleitamento, provavelmente em função do desenvolvimento do rúmen.

A maioria dos trabalhos de pesquisa aponta desempenhos semelhantes aos observados com o leite integral, para bezerros que receberam sucedâneos à base de soro de leite, com nível de inclusão semelhante ao deste trabalho (Tomkins e Jaster, 1991; Terosky et al., 1997; Lammers et al., 1998). Entretanto, cabe aqui a observação de que, na maioria dos trabalhos internacionais, aparecem relatos de que os animais são aleitados por, no mínimo 60 dias, e com quantidades significativamente maiores de sucedâneos. O desempenho pode estar associado, nesses trabalhos, ao maior crescimento, e conseqüente consumo de alimentos sólidos, que minimizariam as diferenças relativas à composição dos sucedâneos e do leite.

O desempenho inferior apresentado pelos bezerros do grupo $\mathrm{S}$ pode ser atribuído a vários fatores. Em relação à composição do sucedâneo $\mathrm{S}$, podem-se formular algumas hipóteses.

Uma delas sugere que a completa ausência de caseína no sucedâneo $\mathrm{S}$ e, conseqüentemente, de coagulação no abomaso, pode propiciar a rápida chegada de grande quantidade de nutrientes no intestino delgado após a alimentação, que talvez gere sobrecarga do sistema digestivo, levando à menor digestão e absorção dos nutrientes. Segundo (Church, 1993), a tensão da parede do abomaso e as altas concentrações de gordura, glicose e aminoácidos, que se observam quando se forma o coágulo, agem retardando o processo de esvaziamento gástrico. Embora a maior parte dos trabalhos de pesquisa não tenha mostrado diferenças no desempenho de bezerros aleitados com sucedâneos formadores e não-formadores de coágulos, Jenkins et al. (1982) observaram ganho de peso $23 \%$ menor na ausência de coagulação.

Outra hipótese é a de que, entre as proteínas lácteas, a caseína e a alfa-lactoalbumina sérica são extensivamente hidrolisadas no abomaso. Entretanto, a beta-lactoglobulina sérica é relativamente inalterada pelas enzimas do abomaso, sendo digerida principalmente no intestino delgado (Church, 1993). Com a substituição do leite integral por soro e a ausência de coagulação no abomaso, maior quantidade dessa proteína chegará ao sítio digestivo, podendo sobrecarregá-lo, e ocasionar menor aproveitamento da dieta líquida. Terosky et al. (1997) sugeriram a adição de lisina em sucedâneos à base de proteínas do soro. Embora esses autores não informassem os motivos dessa estratégia, é possível que seja para minimizar os efeitos da menor absorção decorrente da sobrecarga intestinal.

Uma terceira hipótese sugere que, embora a maioria das alterações nas concentrações plasmáticas dos hormônios sofra influência principal da idade e do desaleitamento, o aumento na velocidade de passagem da digesta para o intestino delgado também pode modificar o padrão normal de secreção de hormônios metabólicos e gastrintestinais, alterando o desenvolvimento funcional e os processos digestivos e absortivos (Le Drean et al., 1998). A chegada de grande quantidade de aminoácidos e gorduras ao intestino delgado pode gerar, por exemplo, um pico de somatostatina, resultando em inibição da secreção de hormônios e enzimas gastrintestinais e pancreáticas. Além disso, a 
somatostatina possui efeitos antiproliferativos, podendo retardar o desenvolvimento funcional da mucosa intestinal (Baldwin et al., 2004).

Outra hipótese sugere que a rápida absorção de glicose pode também ter alterado o padrão normal de secreção de insulina, que está envolvida com o crescimento epitelial do intestino delgado. $\mathrm{O}$ primeiro pico de insulina ocorre cerca de uma hora após o aleitamento, coincidindo com a passagem do soro do leite, contendo carboidratos e $\mathrm{N}$ solúvel, para o intestino delgado. $\mathrm{O}$ segundo pico ocorre três a quatro horas mais tarde (Church, 1993) e pode estar relacionado à absorção de alguns aminoácidos específicos, como tirosina, valina, isoleucina, e fenilalanina (Herdt, 2004), provenientes da quebra da caseína retida no coágulo. Assim, pode-se especular que dietas não-formadoras de coágulo no abomaso talvez não propiciem o aparecimento do segundo pico de insulina, afetando negativamente o desenvolvimento intestinal. Para confirmação desse efeito, seria necessária a determinação da curva plasmática de insulina.

Uma hipótese plausível diz respeito à grande quantidade de substâncias bioativas presentes no leite integral, formadas a partir da digestão enzimática da caseína, como a casecidina, os fosfopeptídeos da caseína (CPP) e a lactoferricina. Esses compostos apresentam funções importantes no desenvolvimento funcional e na atividade imunológica da mucosa intestinal (Clare e Swaisgood, 2000), e não estão presentes em dietas líquidas com ausência de leite integral, como o sucedâneo S.

Finalmente, substâncias tróficas como o fator de crescimento epidermal (EGF) e o fator de crescimento semelhante à insulina (IGF) também podem estar presentes em menores concentrações em formulações que não contêm leite integral, afetando negativamente $\mathrm{o}$ desenvolvimento do trato gastrintestinal (Xu, 1996; Pácha, 2000; Roffler et al., 2003).

\section{CONCLUSÕES}

A substituição de $64,4 \%$ do leite integral por CPS e soro de leite, na formulação de sucedâneos para bezerros, não afetou o consumo de alimentos, e o ganho de peso, sendo opção de dieta líquida para bezerros. A substituição de $100 \%$ do leite integral por CPS e soro de leite afetou negativamente o desempenho dos bezerros, não sendo recomendada a sua utilização. Trabalhos envolvendo dosagens hormonais e estudos morfológicos e morfométricos do trato gastrintestinal são necessários para elucidar os fatores envolvidos no pior desempenho de bezerros aleitados com $100 \%$ de proteínas do soro.

\section{REFERÊNCIAS BIBLIOGRÁFICAS}

BALDWIN, R.L.; McLEOD, K.R.; KLOTZ, J.L. et al. Rumen development, intestinal growth and hepatic metabolism in the pre and postweaning ruminant. J. Dairy Sci., v.87, supl. E, E55-E65, 2004.

CHURCH, D.C. Digestion, metabolism and nutrient needs in preruminantes. In: The ruminant animal digestive physiology and nutrition. Oregon: Metropolitan Printing, 1993. p.401-420.

CLARE, D.A.; SWAISGOOD, H.E. Bioactive milk peptides: a prospectus. J. Dairy Sci., v.83, p.1187-1195, 2000.

CRANE, F.M. Milk replacers move from gruel to worldwide industry. Feedstuffs, v.63, p.18-19, 1991.

DAVIS, C.L.; DRACKLEY, J.K. The development, nutrition and management of the young calf. Iowa: Iowa University, 1998. 329p.

HERDT, T. Fisiologia gastrintestinal e metabolismo. In: CUNNINGHAM, J.G. Tratado de fisiologia veterinária. Rio de Janeiro: Guanabara Koogan, 2004. p.231-330.

JENKINS, K.J.; EMMONS, D.B.; LARMOND, E. et al. Soluble, partially hidrolyzed fish protein concentrate in calf milk replacers. J. Dairy Sci., v.65, p.784-792, 1982.

LAMMERS, B.P.; HEINRICHS, A.J.; AYDIN, A. The effect of whey protein concentrate or dried skim milk in milk replacer on calf performance and blood metabolites. J. Dairy Sci., v.81, p.1940-1945, 1998.

LE DREAN, G.; LE HUEROU-LURON, I.; GESTIN, M. et al. Comparison of the kinetics of pancreatic secretion and gut regulatory peptides in the plasma of preruminant calves fed milk or 
soybean protein. J. Dairy Sci., v.81, p.13131321, 1998.

NUTRIENT requirements of dairy cattle. 7.ed. Washington DC: NRC, 2001, 381p.

OFFICIAL methods of analysis. 13.ed. Washington, DC: AOAC, 1980. 1015p.

PÁCHA, J. Development of intestinal transport function in mammals. Physiol. Rev., v.80, p.1633-1667, 2000.

QUIGLEY III, J.D.; BERNARD, J.K. Milk replacers with or without animal plasma for dairy calves. J. Dairy Sci., v.79, p.1881-1884, 1996.

ROFFLER, B.; FAH, A.; SAUTER, S.N. et al. Intestinal morphology, epithelial cell proliferation, and absorptive capacity in neonatal calves fed milk-born insuline-like-growth factorI or a colostrum extract. J. Dairy Sci., v.86, p.1797-1806, 2003.
SISTEMAS de análises estatísticas e genéticas SAEG. Versão 7.0. Viçosa: UFV, 1998 (Versão 7.0).

TEROSKY, T.L.; HEINRICHS, A.J.; WILSON, L.L. A comparison of milk protein sources in diet of calves up to eight weeks of age. J. Dairy Sci., v.80, p.2977-2983, 1997.

TOMKINS, T.; JASTER, E.H. Pre ruminant calf nutrition. Vet. Clin North Am: Food Anim. Pract., v.7, p.557 -584, 1991.

VAN SOEST, P.J.; ROBERTSON, J.B.; LEWIS, B.A. Methods for dietary fiber, neutral detergent fiber, and non starch polysaccharides in relation to animal nutrition. J. Dairy Sci., v.74, p.35833597, 1991.

XU, R.J. Development of the newborn GI tract and its relation to colostrum/milk intake: a review. Reprod. Fertil Develop., v.8, p.35-48, 1996. 